\title{
AN ANALYSIS OF HEALTH CARE FACILITY SYSTEMS IN PURBA AND PASCHIM BARDHAMAN DISTRICTS, WEST BENGAL, INDIA
}

\author{
Aritra Basak $^{1}$ and Giyasuddin Siddique ${ }^{2}$ \\ ${ }^{1}$ Research Scholar, ${ }^{2}$ Professor, \\ Department of Geography, The University of Burdwan, Burdwan, India \\ Email: gsbu2008@gmail.com, basakaritra5@gmail.com
}

\begin{abstract}
Human health has been globally considered as one of the key indicators of Human Development. The general health condition of the people of an area is indicative of the quality of the health care facilities available in that area. The present study strives to analyse different dimensions of health care facilities to find out the status of health care system of the Purba and Paschim Bardhaman Districts of West Bengal, India. To do so, Health Care Facility Index (HCFI) has been measured to appraise the overall health care condition of these two districts. The Paschim Bardhaman District has revealed comparatively better average HCFI value (0.34) than the Purba Bardhaman District (0.13).
\end{abstract}

Key words: Dimension Index, Health, Health-care Facility, Human Development.

\section{Introduction}

In 1948, the World Health Organization (WHO) defined health as "Health is a state of complete physical, mental and social well-being and not merely the absence of diseases or infirmity" (WHO Constitution). In 1986, WHO redefined health as "A resource for everyday life, not the objective of living. Health is a positive concept emphasizing social and personal resources, as well as physical capacities" (World Health Organization). This indicates that health is a resource to support an individual's activities in society (Husain, 1994). A healthy way of life provides the means to direct a full life (Mishra, 2007). Health care system or health care facilities of a region are obviously influenced by its social and economic conditions (Billings et al., 1993; Bindman et al., 1995; Mishra, 2007; Anthamatten and Hazen, 2011). Health Care Facilities vary across countries, communities and individuals (Joshi, 1997; Krishan, 2001; Singh, 2006; Debapriya and Mahanti, 2000 and 2006; Meade and Earickson, 2006; Singh, 2006). Health Care Systems are the organizations or institutions established to provide health care to the needy people (King and Crews, 2013). As per World Health Organization (WHO), a good health care system deliver quality services to all the people when they need them and it needs a well-trained workforce, well maintained health facilities to deliver quality medicines and treatment (World Health Organization) A well-developed health care system can enhance a country's economic conditions and overall well-being of its citizens (Lakshminarayanan, 2011; Verma et all, 2018). Health care is considered as an important factor to promote the general health and well-being of people across the globe. The present study is an endeavour to analyse the Block wise health care facility system of Purba and Paschim Bardhaman District of West Bengal.

\section{Study Area}

In the present study 23 C.D. Blocks in Purba Bardhaman and 8 C.D. Blocks and 2 Municipal Corporation (M.C.) in Paschim Bardhaman has been considered for area under investigation. The Geographical co-ordinates of the area thus delimited extend from $22^{\circ}{ }^{\circ} 6^{\prime}$ North to $23^{\circ} 53^{\prime}$

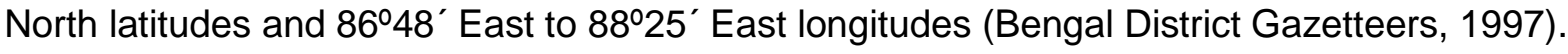

\section{Objectives}

The main objectives of this study are:

1. To find out the Block wise disparity of Health Care Facility (HCF) of Purba and Paschim Bardhaman District and

2. To make the study more in depth with formulation a composite index i.e., Health Care Facility Index (HCFI) has been done and try to find the Block's positions within the District. 
Figure 01: Location Map

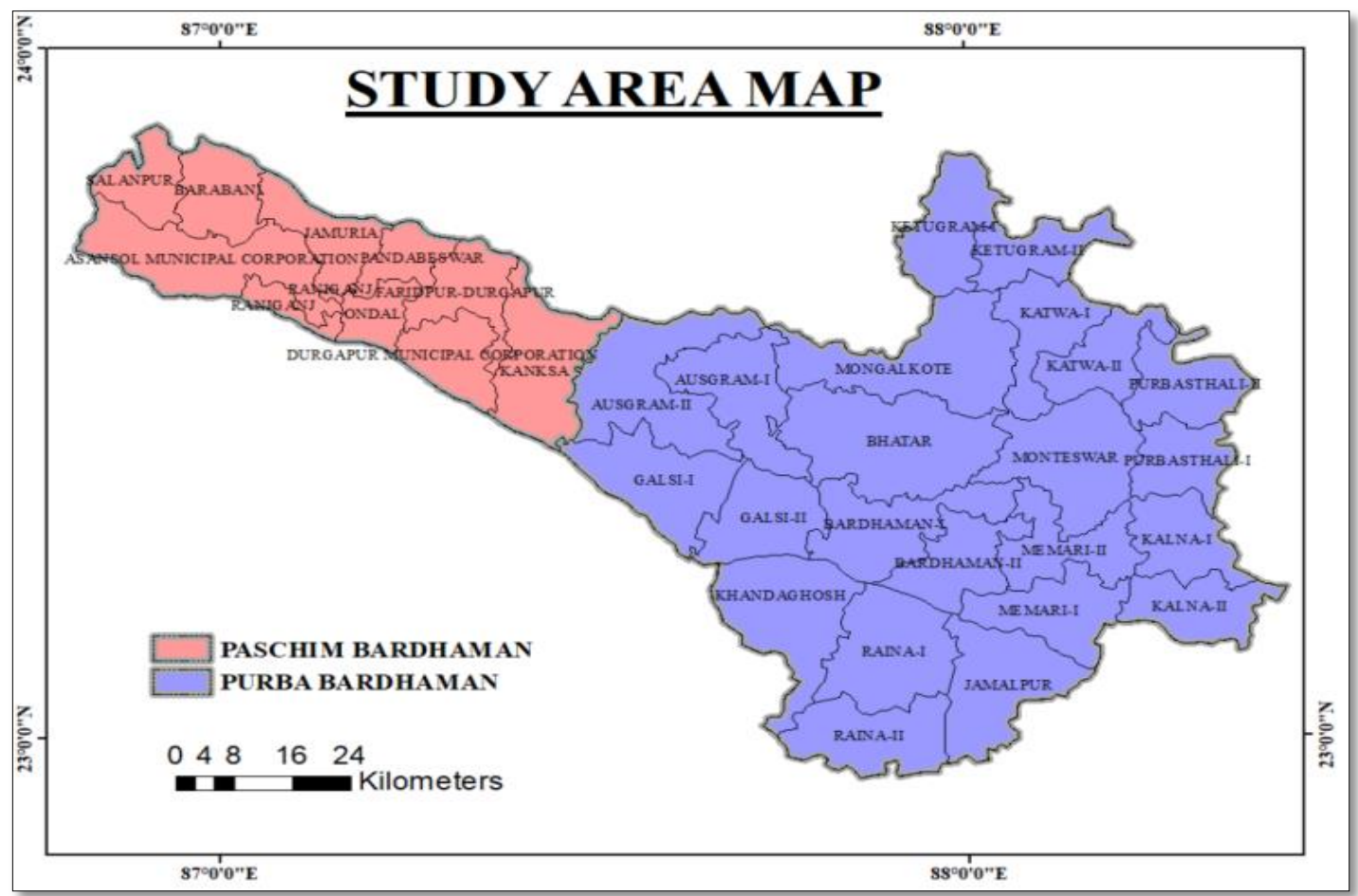

\section{Database}

The study has been conducted on the basis of the secondary database collected from Census of India, 2011 and District Statistical Handbook of Bardhaman, 2014. Total population of Bardhaman, Memari, Kalna, Katwa, Dainhat and Gushkara Municipalities has been added to the populations of respective C.D. Blocks in Purba Bardhaman District. All the Hospitals including Rural Hospitals, Block Primary Health Centers (BPHC), Primary Health Centers (PHC), other clinical Departments of Govt. of West Bengal including State Govt. Undertakings, Local Bodies, and Govt. of India including Central Govt. undertaking, N.G.O. / Private Bodies (Nursing Homes) have been considered as Health Care Institutions $(\mathrm{HCl})$. Total number of beds and total number of Doctors of each C. D. Blocks have been collected from District Statistical Handbook of Bardhaman, 2014.

\section{Methodology}

The methodological steps followed in the present study are:

1. Identification of the Dimensions of Health Care Facility system.

2. Calculation of the identified Dimensions as indices $\left(d_{i}\right)$.

3. The Health Care Facility Index (HCFI) is calculated and analysed for the period of study.

In the present study, five dimensions have been selected to measure the extent of Health Care Facility System. At first, Health Care Facility System of Purba and Paschim Bardhaman Districts have been analysed on the basis of secondary data collected from District Statistical Handbook, Bardhaman, 2014. Five basic Dimensions i.e., Health Care Institution Population Ratio (HCIPR), Bed Population Ratio (BPR), Doctor Population Ratio (DPR), Doctor Health Care Institution Ratio (DHCIR) and Bed Health Care Institution Ratio (BHCIR) of Health Care Facility System have been identified and calculated using the following formulae.

Health Care Institution $(\mathrm{HCl}) \times 1,00,000$

$\mathrm{HCIPR}=$

Total Population

Number of $\mathrm{Bed}$ in $\mathrm{HCl} \times 10,000$

$\mathrm{BPR}=$

Total Population

Number of Doctor in $\mathrm{HCl} \times 1,00,000$

Total Population 
Number of Doctor in $\mathrm{HCl}$

DHCIR $=$ - Health Care Institution $(\mathrm{HCl})$

Number of Bed in $\mathrm{HCl}$

$\mathrm{BHCIR}=$

Health Care Institution $(\mathrm{HCl})$

Table 01: Health Care Facilities of Purba Bardhaman

\begin{tabular}{|c|c|c|c|c|c|}
\hline \multirow[b]{2}{*}{$\#$} & \multirow[b]{2}{*}{ C. D. Blocks } & \multirow{2}{*}{$\begin{array}{l}\text { Total Population } \\
\text { (2011) }\end{array}$} & \multicolumn{3}{|c|}{ Health Care Delivery System } \\
\hline & & & $\begin{array}{c}\text { Health Care } \\
\text { Institution }(\mathrm{HCl})\end{array}$ & $\begin{array}{l}\text { Total No. of } \\
\text { Beds }\end{array}$ & $\begin{array}{l}\text { Total No. of } \\
\text { Doctors }\end{array}$ \\
\hline 1 & Ausgram-I & 154751 & 8 & 136 & 14 \\
\hline 2 & Ausgram-II & 150896 & 6 & 39 & 7 \\
\hline 3 & Galsi-I & 187588 & 6 & 53 & 7 \\
\hline 4 & Galsi-II & 147177 & 3 & 29 & 3 \\
\hline 5 & Bardhaman-I & 530208 & 66 & 2558 & 509 \\
\hline 6 & Bardhaman-II & 152939 & 5 & 16 & 4 \\
\hline 7 & Bhatar & 263064 & 9 & 84 & 10 \\
\hline 8 & Memari-I & 259876 & 9 & 125 & 10 \\
\hline 9 & Memari-II & 150252 & 4 & 32 & 5 \\
\hline 10 & Jamalpur & 266338 & 8 & 98 & 8 \\
\hline 11 & Raina-I & 180952 & 8 & 51 & 6 \\
\hline 12 & Raina-II & 151401 & 6 & 39 & 8 \\
\hline 13 & Khandaghosh & 189336 & 4 & 29 & 4 \\
\hline 14 & Mongalkote & 263240 & 6 & 81 & 10 \\
\hline 15 & Ketugram-I & 165408 & 3 & 28 & 5 \\
\hline 16 & Ketugram-II & 118567 & 3 & 25 & 3 \\
\hline 17 & Katwa-I & 279099 & 13 & 293 & 37 \\
\hline 18 & Katwa-II & 136708 & 3 & 25 & 4 \\
\hline 19 & Purbasthali-I & 206977 & 4 & 44 & 4 \\
\hline 20 & Purbasthali-II & 212355 & 5 & 37 & 5 \\
\hline 21 & Kalna-I & 263667 & 24 & 451 & 24 \\
\hline 22 & Kalna-II & 167335 & 5 & 40 & 7 \\
\hline 23 & Monteswar & 237398 & 5 & 47 & 5 \\
\hline \multicolumn{6}{|c|}{ Health Care Facilities of Paschim Bardhaman District } \\
\hline 1 & Kanksa & 178125 & 8 & 39 & 4 \\
\hline 2 & Faridpur-Durgapur & 115924 & 3 & 27 & 4 \\
\hline 3 & Pandabeswar & 161891 & 2 & 6 & 1 \\
\hline 4 & Ondal & 186915 & 12 & 274 & 40 \\
\hline 5 & Jamuria & 123176 & 5 & 93 & 20 \\
\hline 6 & Raniganj & 106441 & 9 & 107 & 8 \\
\hline 7 & Barabani & 127542 & 6 & 35 & 7 \\
\hline 8 & Salanpur & 163057 & 7 & 517 & 52 \\
\hline 9 & Durgapur M.C. & 566517 & 37 & 1688 & 315 \\
\hline 10 & Asansol M.C. & 1152443 & 97 & 3647 & 479 \\
\hline
\end{tabular}

Source: Census of India, 2011; District Statistical Handbook- Bardhaman, 2014

\section{Dimension 1}

Health Care Institution Population Ratio (HCIPR): This dimension is used to find out the number of population served by a single health care institution in the study area. In Purba Bardhaman District, Bardhaman I C.D. Block enjoys the best position in this dimension whereas, Ketugram I has the worst condition. On the other hand, in Paschim Bardhaman District, Raniganj has the highest number of health care institution per one lakh of population and Pandabeswar has the lowest number of health care institution per one lakh of population.

\section{Dimension 2}

Bed Population Ratio (BPR): Bed Population Ratio is used to measure the number of beds available per 10000 populations. In Purba Bardhaman, Bardhaman I has the highest BPR where Bardhaman II has the lowest being in very poor condition. On contrary, Salanpur C.D. Block of Paschim Bardhaman District enjoys the best position in this dimension whereas Pandabeswar occupies the last position with very poor BPR. 
Table 02: Health Care Facility Dimensions of Purba Bardhaman

\begin{tabular}{|c|c|c|c|c|c|c|}
\hline$\#$ & C. D. Blocks & HCIPR & BPR & DPR & DHCIR & BHCIR \\
\hline 1 & Ausgram-I & 5.17 & 8.79 & 9.05 & 1.75 & 17 \\
\hline 2 & Ausgram-II & 3.98 & 2.58 & 4.64 & 1.12 & 6.5 \\
\hline 3 & Galsi-I & 3.20 & 2.82 & 3.73 & 1.17 & 8.83 \\
\hline 4 & Galsi-II & 2.04 & 1.97 & 2.04 & 1 & 9.67 \\
\hline 5 & Bardhaman-I & 12.45 & 48.24 & 96.00 & 7.71 & 38.76 \\
\hline 6 & Bardhaman-II & 3.27 & 1.05 & 2.61 & 0.8 & 3.2 \\
\hline 7 & Bhatar & 3.42 & 3.19 & 3.80 & 1.11 & 9.33 \\
\hline 8 & Memari-I & 3.46 & 4.81 & 3.85 & 1.11 & 13.89 \\
\hline 9 & Memari-II & 2.66 & 2.13 & 3.33 & 1.25 & 8 \\
\hline 10 & Jamalpur & 3.00 & 3.68 & 3.00 & 1 & 12.25 \\
\hline 11 & Raina-I & 4.42 & 2.82 & 3.31 & 0.75 & 6.37 \\
\hline 12 & Raina-II & 3.96 & 2.57 & 5.28 & 1.33 & 6.5 \\
\hline 13 & Khandaghosh & 2.11 & 1.53 & 2.11 & 1 & 7.25 \\
\hline 14 & Mongalkote & 2.28 & 3.08 & 3.80 & 1.67 & 13.5 \\
\hline 15 & Ketugram-I & 1.81 & 1.69 & 3.02 & 1.67 & 9.33 \\
\hline 16 & Ketugram-II & 2.53 & 2.11 & 2.53 & 1 & 8.33 \\
\hline 17 & Katwa-I & 4.66 & 10.50 & 13.26 & 2.85 & 22.54 \\
\hline 18 & Katwa-II & 2.19 & 1.83 & 2.92 & 1.33 & 8.33 \\
\hline 19 & Purbasthali-I & 1.93 & 2.12 & 1.93 & 1 & 11 \\
\hline 20 & Purbasthali-II & 2.35 & 1.74 & 2.35 & 1 & 7.4 \\
\hline 21 & Kalna-I & 9.10 & 17.10 & 9.10 & 1 & 18.79 \\
\hline 22 & Kalna-II & 2.99 & 2.39 & 4.18 & 1.4 & 8 \\
\hline 23 & Monteswar & 2.11 & 1.98 & 2.10 & 1 & 9.4 \\
\hline \multicolumn{7}{|c|}{ Health Care Facility Dimensions of Paschim Bardhaman } \\
\hline 1 & Kanksa & 4.49 & 2.19 & 2.24 & 0.5 & 4.87 \\
\hline 2 & Faridpur-Durgapur & 2.59 & 2.33 & 3.45 & 1.33 & 9 \\
\hline 3 & Pandabeswar & 1.23 & 0.37 & 0.62 & 0.5 & 3 \\
\hline 4 & Ondal & 6.42 & 14.66 & 21.40 & 3.33 & 22.83 \\
\hline 5 & Jamuria & 4.06 & 7.55 & 16.24 & 4 & 18.6 \\
\hline 6 & Raniganj & 8.45 & 10.05 & 7.52 & 0.89 & 11.89 \\
\hline 7 & Barabani & 4.70 & 2.74 & 5.49 & 1.17 & 5.83 \\
\hline 8 & Salanpur & 4.29 & 31.71 & 31.89 & 7.43 & 73.86 \\
\hline 9 & Durgapur M.C. & 6.53 & 29.80 & 55.60 & 8.51 & 45.62 \\
\hline 10 & Asansol M.C. & 8.42 & 31.64 & 41.56 & 4.94 & 37.60 \\
\hline
\end{tabular}

Source: Census of India, 2011; District Statistical Handbook- Bardhaman, 2014 and author' calculation

\section{Dimension 3}

Doctor Population Ratio (DPR): This dimension indicates the number of doctors per one lakh of population in the study area. The Planning Commission of India has suggested the Doctor Population Ratio should be 1:1000 (Planning Commission of India, 2011) but here we find that none of the Blocks in both Districts can achieve this critical limit of BPR. In Purba Bardhaman District, Bardhaman I has the highest DPR where Purbasthali I has the lowest ratio. On the other hand in Paschim Bardhaman District, Durgapur Municipal Corporation has the best condition and Pandabeswar has the worst condition within the District.

\section{Dimension 4}

Doctor Health Care Institution Ratio (DHCIR): This dimension is used to find out the number of doctor per health care institution in the study area. Here, after the analysis of dataset, we have found out that in Purba Bardhaman District, Bardhaman I C.D. Block has the highest number of doctor to attain a health care institution where Raina I has the worst condition. In Paschim Bardhaman District Durgapur M.C. has the best condition whereas Kanksa and Pandabeswar possess the last position. 


\section{Dimension 5}

Bed Health Care Institution Ratio (BHCIR): This dimension is used to measure the number of bed per health care institution in the study area. The more number of beds available in a health care institution indicates the good condition of health care facilities in that region. In Purba Bardhaman District, Bardhaman I have the best condition where Bardhaman II has the worst condition. On the other hand, in Paschim Bardhaman District, Salanpur is in the best position whereas Pandabeswar is in the lowest position.
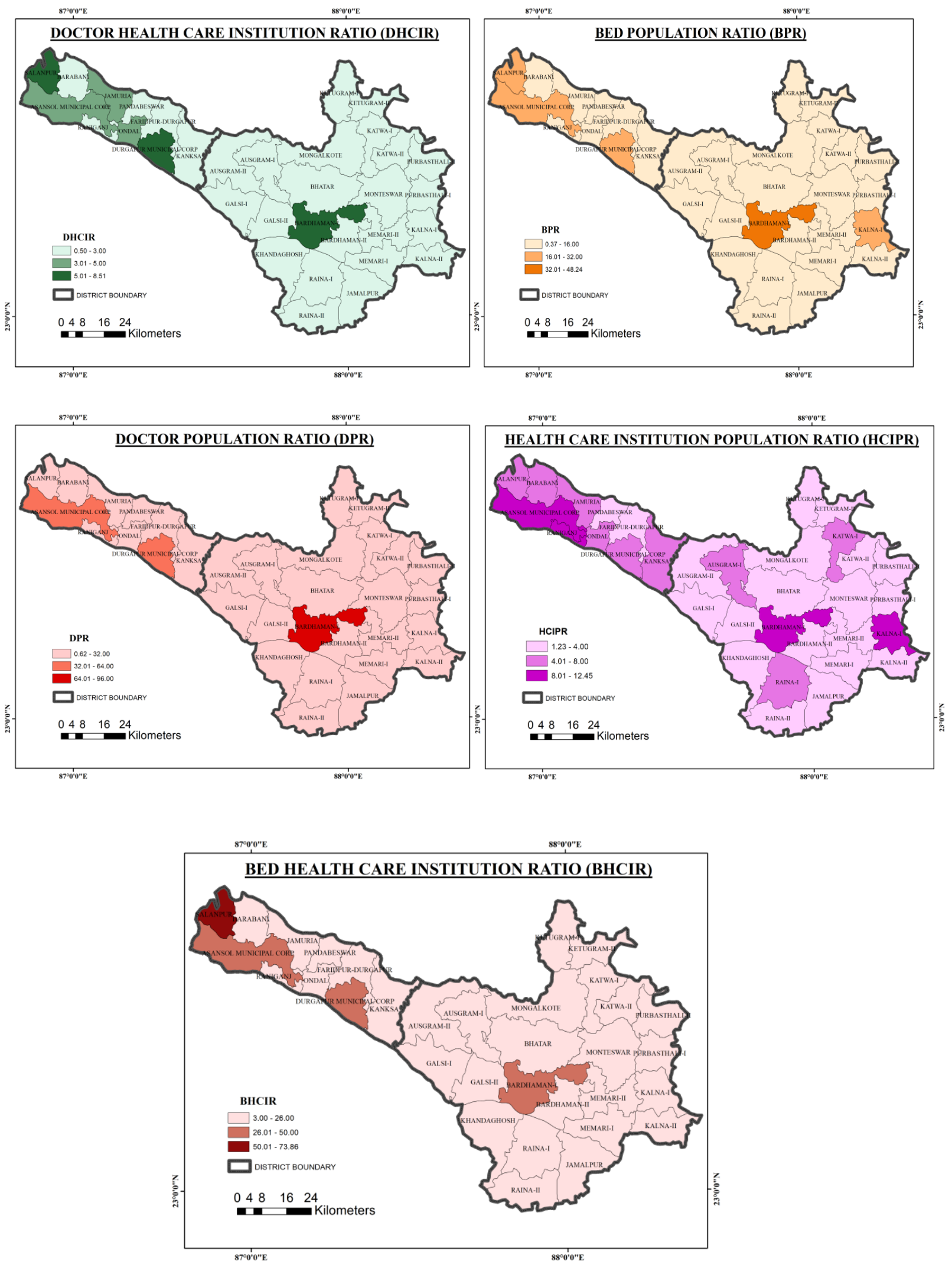
Table 03: Health Care Facility Dimensions and their Domestic Goalpost of Purba and Paschim Bardhaman District

\begin{tabular}{|c|c|c|}
\hline \multirow{2}{*}{ Dimensions } & \multicolumn{2}{|c|}{ Goalposts of the Dimensions } \\
\hline & Minimum Value & Maximum Value \\
\hline \multirow{2}{*}{$\begin{array}{l}\text { Health Care Institution Population } \\
\text { Ratio (HCIPR) }\end{array}$} & 1.81 (Ketugram-I) & 12.45 (Bardhaman-I) \\
\hline & 1.23 (Pandabeswar) & 8.45 (Raniganj) \\
\hline \multirow{2}{*}{ Bed Population Ratio (BPR) } & 1.05 (Bardhaman-II) & 48.24 (Bardhaman-I) \\
\hline & 0.37 (Pandabeswar) & 31.71 (Salanpur) \\
\hline \multirow{2}{*}{ Doctor Population Ratio (DPR) } & 1.93 (Purbasthali-I) & 96.00 (Bardhaman-I) \\
\hline & 0.62 (Pandabeswar) & 55.60 (Durgapur M.C.) \\
\hline \multirow{2}{*}{$\begin{array}{l}\text { Doctor Health Care Institution } \\
\text { Ratio (DHCIR) }\end{array}$} & 0.75 (Raina-I) & 7.71 (Bardhaman-I) \\
\hline & 0.5 (Kanksa, Pandab & 8.51 (Durgapur M.C.) \\
\hline \multirow{2}{*}{$\begin{array}{l}\text { Bed Health Care Institution Ratio } \\
\text { (BHCIR) }\end{array}$} & 3.2 (Bardhaman-II) & 38.76 (Bardhaman-I) \\
\hline & 3 (Pandabeswar) & 73.85 (Salanpur) \\
\hline
\end{tabular}

Source: Authors' computation based on secondary data

The minimum and maximum values of Health Care Facilities observed among the Blocks are noted down in Table No. 3. The dimension index $\left(d_{i}\right)$ is calculated in order to construct the Health Care Facility Index (HCFI) based on the following formula:

$$
d_{i}=\frac{A_{i}-m_{i}}{M_{i}-m_{i}}
$$

Where, $d_{i}=$ Dimension index of $i^{\text {th }}$ dimension, $A_{i}=$ Actual value of $i^{\text {th }}$ dimension, $M_{i}=$ Maximum Value of $i^{\text {th }}$ dimension and $m_{i}=$ Minimum Value of $i^{\text {th }}$ dimension.

In UNDP Goal Post method, calculation is done with the predetermined values for the minimum and maximum values. On the other hand, in this method, we have used the observed minimum and maximum values for each dimension. The dimension $\left(d_{i}\right)$ value ranges between 0 to 1 (Goel and Sharma 2017). High dimensional value $\left(d_{i}\right)$ indicates higher success of the C.D. Blocks/Municipal Corporation in $i^{\text {th }}$ dimension.

Considering all the five dimensions,,$i^{\text {th }}$ C. D. Block can be represented by a point $\left(d_{1}, d_{2}, d_{3}\right)$ in three-dimensional Cartesian space like $0 \leq d_{1}, d_{2}, d_{3} \leq 1$. In the three-dimensional Cartesian space, the point ' 0 ' would indicate the worst condition whereas ' 1 ' would indicate the ideal or perfect condition. HCFI is measured by the normalized inverse Euclidean distance of the point $\left(d_{1}, d_{2}, d_{3}\right)$ from the best or perfect point $(1,1,1)$.

Therefore, taking into account the equal weight for each dimension we can explain the formula for calculation of $\mathrm{HCFI}$ as follows.

$$
H C F I=1-\sqrt{\frac{\left(1-\mathrm{d}_{1}\right)^{2}+\left(1-\mathrm{d}_{2}\right)^{2}+\left(1-\mathrm{d}_{3}\right)^{2}}{5}}
$$

The value of $\mathrm{HCFI}$ ranges from ' 0 ' to ' 1 '. The value ' 0 ' indicates the worst health care facilities system and ' 1 ' indicates the Perfect health care facilities. On the basis of the HCFI values, the C. D. Blocks are classified into three categories. The range $0.5<\mathrm{HCFl} \leq 1$ indicates 'High' or 'Very Good' health care facility system; $0.2<\mathrm{HCFI} \leq 0.5$ indicates 'Moderate' health care facility system and $0 \leq \mathrm{HCFI} \leq 0.2$ 'Low' or 'Poor' health quality facility system.

After the Block wise calculation of Health Care Facility Index (HCFI) of Purba and Paschim Bardhaman District, we have placed each Blocks according to their rank. Table number 4 and 5 portrays the rank wise distribution of each Block of two Districts. In Purba Bardhaman District, Bardhaman I gets the first position with HCFI value of 1 . So, we can say that Bardhaman I has the perfect condition of health care facilities. Bardhaman I get the first position due to the good health care facilities of Bardhaman Municipality which has been added with this Block. Kalna I, Katwa I, and Ausgram I follow respectively with the $2^{\text {nd }}, 3^{\text {rd }}$ and $4^{\text {th }}$ position. These three Blocks are considered under the medium or moderate condition of health care facilities. Whereas, rest of the 19 Blocks of this District fall under very poor condition of health care facilities. The last three Blocks are in this list are Purbasthali II, Khandaghosh and Bardhaman II. 
Table 04: Health Care Facility Index (HCFI) of Purba Bardhaman District, 2014

\begin{tabular}{|c|c|c|c|c|}
\hline$\#$ & Blocks & $\mathrm{HCFI}$ & Rank & Remarks \\
\hline 1. & Bardhaman-I & 1.0000 & 1 & High \\
\hline 2. & Kalna-I & 0.2744 & 2 & Medium \\
\hline 3. & Katwa-I & 0.2725 & 3 & Medium \\
\hline 4. & Ausgram-I & 0.2089 & 4 & Medium \\
\hline 5. & Memari-I & 0.1159 & 5 & Low \\
\hline 6. & Mongalkote & 0.1001 & 6 & Low \\
\hline 7. & Jamalpur & 0.0897 & 7 & Low \\
\hline 8. & Raina-II & 0.0873 & 8 & Low \\
\hline 9. & Bhatar & 0.0861 & 9 & Low \\
\hline 10. & Ausgram-II & 0.0812 & 10 & Low \\
\hline 11. & Galsi-I & 0.0795 & 11 & Low \\
\hline 12. & Kalna-II & 0.0772 & 12 & Low \\
\hline 13. & Raina-I & 0.0730 & 13 & Low \\
\hline 14. & Memari-II & 0.0639 & 14 & Low \\
\hline 15. & Ketugram-I & 0.0631 & 15 & Low \\
\hline 16. & Katwa-II & 0.0569 & 16 & Low \\
\hline 17. & Purbasthali-I & 0.0543 & 17 & Low \\
\hline 18. & Ketugram-II & 0.0540 & 18 & Low \\
\hline 19. & Monteswar & 0.0498 & 19 & Low \\
\hline 20. & Galsi-II & 0.0496 & 20 & Low \\
\hline 21. & Purbasthali-II & 0.0440 & 21 & Low \\
\hline 22. & Khandaghosh & 0.0372 & 22 & Low \\
\hline 23. & Bardhaman-II & 0.0288 & 23 & Low \\
\hline
\end{tabular}

Source: Authors' computation based on secondary data)

Table 05: Health Care Facility Index (HCFI) of Paschim Bardhaman District, 2014

\begin{tabular}{|c|l|c|c|c|}
\hline$\#$ & \multicolumn{1}{|c|}{ Blocks } & HCFI & Rank & Remarks \\
\hline 1. & Durgapur M.C. & 0.7838 & 1 & High \\
\hline 2. & Asansol M.C. & 0.6756 & 2 & High \\
\hline 3. & Salanpur & 0.6724 & 3 & High \\
\hline 4. & Ondal & 0.4169 & 4 & Medium \\
\hline 5. & Jamuria & 0.3066 & 5 & Medium \\
\hline 6. & Raniganj & 0.2367 & 6 & Medium \\
\hline 7. & Barabani & 0.1378 & 7 & Low \\
\hline 8. & Kanksa & 0.0968 & 8 & Low \\
\hline 9. & Faridpur-Durgapur & 0.0967 & 9 & Low \\
\hline 10. & Pandabeswar & 0.0000 & 10 & Low \\
\hline
\end{tabular}

Source: Authors' computation based on secondary data

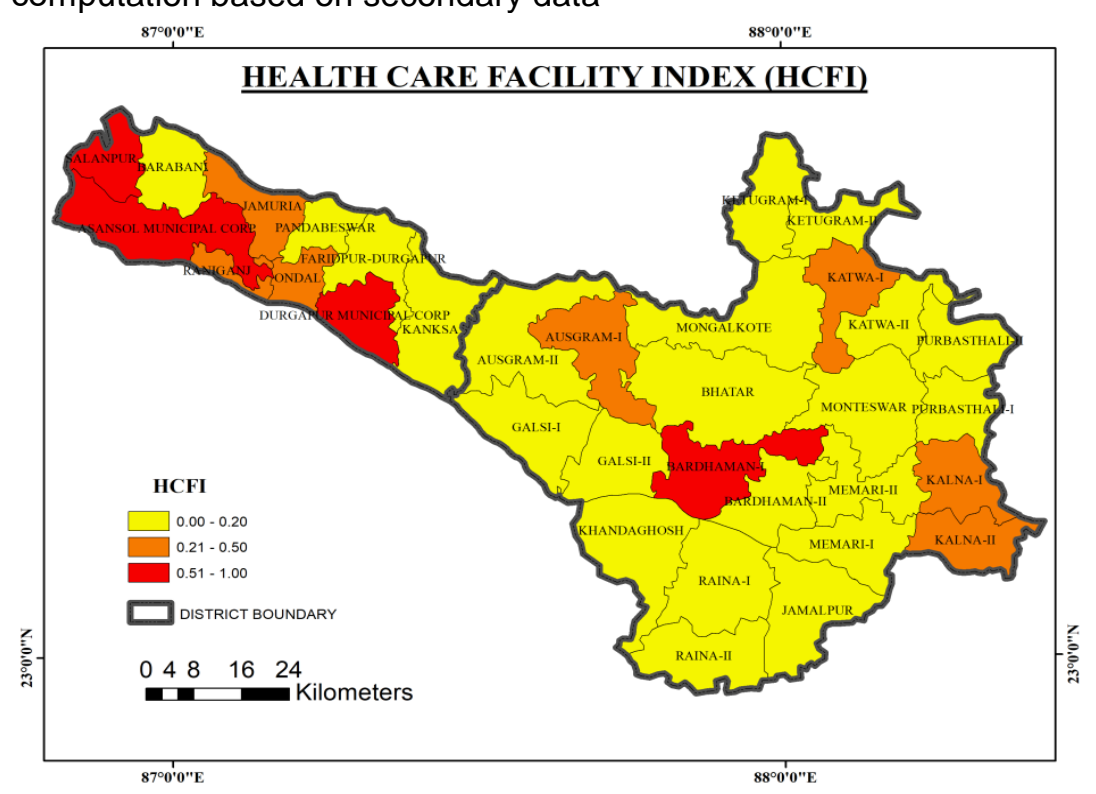


The Durgapur Municipal Corporation in Paschim Bardhaman District claims the first position with HCFI value of 0.78 . The next two ranks are hold by Asansol M.C. and Salanpur C.D. Block. The first three positions are under very good condition of health care facilities. Ondal, Jamuria and Raniganj Blocks have moderate condition of health care facilities with the $\mathrm{HCFI}$ value ranging between 0.2-0.5. The rest four Blocks like Barabani, Kanksa, FaridpurDurgapur and Pandabeswar have very poor health care facilities. Pandabeswar has the worst condition of health care facilities with the HCFI value of 0 .

Table 06: Health Care Facility Dimensions of the Purba and Paschim Bardhaman District

\begin{tabular}{|c|c|c|c|c|c|c|c|}
\hline District & Statistics & HCIPR & BPR & DPR & DHCIR & BHCIR & HCFI \\
\hline \multirow{4}{*}{$\begin{array}{c}\text { Purba } \\
\text { Bardhaman } \\
\text { District }\end{array}$} & Mean & 3.70 & 5.68 & 8.17 & 1.52 & 11.49 & 0.13 \\
\cline { 2 - 8 } & Median & 3.00 & 2.57 & 3.33 & 1.11 & 9.33 & 0.08 \\
\cline { 2 - 8 } & S.D. & 2.47 & 9.98 & 19.34 & 1.41 & 7.41 & 0.20 \\
\cline { 2 - 8 } & C.V. & 66.71 & 175.50 & 236.64 & 98.99 & 64.50 & 151.49 \\
\cline { 2 - 8 } & Skewness & 2.63 & 3.91 & 4.64 & 4.14 & 2.56 & 4.01 \\
\cline { 2 - 8 } & Kurtosis & 7.44 & 16.45 & 21.95 & 18.29 & 8.03 & 17.44 \\
\cline { 2 - 8 } & Min Value & 1.81 & 1.05 & 1.93 & 0.75 & 3.2 & 0.03 \\
\hline \multirow{4}{*}{$\begin{array}{c}\text { Paschim } \\
\text { Bardhaman } \\
\text { District }\end{array}$} & Mealue & 12.45 & 48.24 & 96.00 & 7.71 & 38.76 & 1.00 \\
\cline { 2 - 8 } & Median & 5.12 & 13.30 & 18.60 & 3.26 & 23.31 & 0.34 \\
\cline { 2 - 8 } & S.D. & 4.60 & 8.80 & 11.87 & 2.33 & 15.24 & 0.27 \\
\cline { 2 - 8 } & C.V. & 45.83 & 12.97 & 18.86 & 2.93 & 22.78 & 0.28 \\
\cline { 2 - 8 } & Skewness & 0.012 & 0.67 & 0.99 & 0.83 & 1.39 & 0.50 \\
\cline { 2 - 8 } & Kurtosis & -0.60 & -1.46 & -0.10 & -0.63 & 1.54 & -1.38 \\
\cline { 2 - 8 } & Min Value & 1.23 & 0.37 & 0.61 & 0.5 & 3 & 0.00 \\
\cline { 2 - 8 } & Max Value & 8.45 & 31.71 & 55.6 & 8.51 & 73.85 & 0.78 \\
\hline
\end{tabular}

Source: Authors' computation based on DSH data, 2014

Table No. 6 shows the descriptive statistics of different dimensions of Health Care Facilities of Purba and Paschim Bardhaman Districts. In Purba Bardhaman District, the mean value of Health Care Institution Population Ratio is 3.70 whereas in Paschim Bardhaman District the mean value of HCIPR is 5.12. So, the number of Health Care Institution per lakh population is more in Paschim Bardhaman District than Purba Bardhaman District. The number of bed in health care institutions per 10000 populations is in better numbered in Paschim Bardhaman District with 13.30/10000 population where in Purba Bardhaman District this number is only 5.68/10000 population. The average Doctor Population Ratio is 8.17 in Purba Bardhaman District per one lakh population whereas average DPR is 18.60 in Paschim Bardhaman District. The average value of number of bed per Health Care Institutional Ratio is 23.31 in Paschim Bardhaman District whereas in Purba Bardhaman District the BHCIR is 11.49. Thus, in all respect, Paschim Bardhaman District possesses better position than Purba Bardhaman in health care facility system.

\section{Conclusion}

Health care facility is one of the basic indicators to measure the wellbeing of a society. In this study different dimensions of health care facilities have been measured to analyse the health care system of Purba and Paschim Bardhaman District. Health Care Facility Index (HCFI) value of each Block shows the health care facilities condition and position of those Blocks within the District. The Mean HCFI value of Purba Bardhaman District is 0.13 which indicates very low situation of health care facilities of this District. On the other hand, the mean value of $\mathrm{HCFI}$ of Paschim Bardhaman District is 0.34 which indicates moderate health care facilities condition of this District. The Government may look for a way to enhance the quality of health care facilities from the grassroots level since wellbeing of a society is closely associated with the improvement of the health care facilities of that region.

\section{References}

1. Anthamatten, P. and Hazen, H. (2011). The Geography of Health. Routledge. 144-164

2. Bengal District Gazetteers, 1997.

3. Billings J, Zeitel L, Lukomnik J, Carey TS, Blank AE, Newman L. (1993). Impact of socioeconomic status on hospital use in New York City. Health Affairs 12(1):162-173. 
4. Bindman AB, Grumbach K, Osmond D, Komaromy M, Vranizan K, Lurie N, Billings J, Stewart A. (1995). Preventable hospitalizations and access to health care. Journal of the American Medical Association 274:305-311.

5. Census of India, 2011.

6. Debapriya, A. and Mohanty, M.K. (2000). Inter District Variation in the Level of Human development in Orissa, Utkal Economic paper, vol-12, pp.50-53

7. Debapriya, A. and Mohanty, M.K. (2006). Inter District Variation in the level of Industrial Development of Orissa: A Quantitative Analysis, Asian Economic Review, Vol. 48, No.1.

8. Goel, S. and Sharma, R. (2017). Developing a Financial Inclusion Index for India. Procedia Computer Science, 122, 949-956. https://www.sciencedirect.com /science/ article/pii/S1877050917327102

9. Government of West Bengal (2014). District Statistical Handbook, Eastern Burdwan 2014. Kolkata: Bureau of Applied Economics and Statistics.

10. https://www.who.int/about/who-we-are/constitution

11. Husain, M. (1994). Medical Geography. Anmol Publications Pvt Ltd, New Delhi, pp. 1-37

12. Joshi, Samir (1997). Regional Disparities in Industrial Development, Indian Journal of Regional Science, Vol. 29, No.1.

13. King, B. and Crews, K. (2013). Ecologies and Politics of Health. Routledge, 13-54

14. Krishan, G. (2001). Presidential address:. Development, Environment and Decentralized planning, Annals of NAGI, Vol. 21, No.1, Jan- 2001pp.2-22.

15. Lakshminarayanan, S. (2011). Role of government in public health: Current scenario in India and future scope. J Family Community Med. 2011 Jan-Apr; 18(1): 26-30. https://dx.doi.org/10.4103\%2F1319-1683.78635

16. Meade, M. and Earickson, R. (2006). Medical Geography. Rawat Publications. New Delhi. 310-342

17. Mishra, R. (2007). Geography of Health. Concept Publishing Company, New Delhi, 60-69

18. Singh R. (2006). Regional Disparities in level of socio-economic Development in post Reforms Period: A District level Analysis, Annals of NAGI, Vol. 26, Dec., No.2, pp.87-94.

19. Verma, C. S.; Singh, S.; Ranjan, A. and Sundararaman, T. (2018). Social and Systematic Determinants of Utilisation of Public Healthcare Services in Uttar Pradesh. Economic and Political Weekly, LIII (45), 54-62. 